\title{
DETECTION OF ADULTERATION IN PETROLEUM PRODUCTS USING A HIGH-SENSITIVITY FLOAT
}

IDONGESIT A. UMOREN

(Received 24 October, 2003; Revision Accepted 6 Feb. 2004)

\section{ABSTRACT}

\begin{abstract}
A high-sensitivity float capable of showing significant depth variations in the range of petroleum products hasi been fabricated using locally available materials and has subsequently been used to detect minor adulteration it: Petroleum Methylated Spirit (PMS), commonly called petrol, and Household Kerosene (HHK), commonly called kerosenc. The degree of sensitivity varies depending on the type of contaminant introduced into a given pure sample. Sensitivity levels in percentage by volume of contaminarits are $4 \%(1: 25), 2 \%(1: 50)$, and $2 \%(1: 50)$ for Automobile Gasoline oil (AGO), commonly called diesel; kerosene (HHK), and lubricant (engine oil) contaminants respectively in 250ml of purt: petrol (PMS) sample; and $6 \%(3: 50), 4 \%(1: 25)$, and $4 \%(1: 25)$ for PMS, AGO, and lubricant contaminants respectively in $250 \mathrm{ml}$ pure sample of HHK. The high degree of sensitivity of the present device makes it a simple and tificie? instrument invaluable in curtailing domestic and industrial hazards often associated with petroleum products adulteration.
\end{abstract}

\section{KEYWORDS: Sensitivity, Petroleum, Adulteration, Density}

\section{INTRODUCTION}

Hydrometers are instruments conventionally designed for measuring the relative densities of a variety of liquid substances and incorporate a floating glass bulb calibrated ior this purpose. Due to the wide range of relative densities that may be determined, the sensitivity of this instrument, which is a function of the design of its float, becomes inappropriate for discriminating between liquids having very close values of relative densities (talk less of using such instrument for detecting slighi changes in their relative densities) arising from slight levels of adulteration.

Petroleum products are hydrocarbon fractions obtained from the processing of crude oil. These products include natural gas, aviation fuel. industrially called Aviation Turbine Kerosene (ATK), gasoline or petrol, industrially referred to as Petroleum Methylated Spirit (PMS), Automobile Gasoline oil (AGO) or diesel, Household Kerosene (HHK), simply called kerosene, and lubricanis, commonly known as engine oil. These products have found increasing use largely as fuel (both domestically and industrially) following the demands of modernization and high technology and the current global campaign for environmental protection and preservation. Afforestation has equally become a programme occupying a centre stage in many tropical countries of the world following desert encroachment, thus leading to the increasing reliance of many societies today on petroleum products for fuel.

In refining crude oil, techniques such as catalytic refining, hydrocracking, isomerization, alkylation, dimerization, among others are usually employed in order to improve the quantity and quality of the processed crude (Hatch and Mater, 1981; Ababio, 1985). Through the refining process, various hydrocarbon fractions, which can be distinguished and described in terms of flash point, pour point, steam point, cloud point, odour, and other properties, are obtained. These fractions, however, have as their principal chemical constituents, carbon and hydrogen. Sulphur compounds and few other compounds such as iron, calcium, aluminium, and nitrogen also exist in some cases as evident in the ash content of these fractions (Bland and Davidson, 1967).

While chemical and other properties of hydrocarbon fractions mentioned here can fairly differentiate a given fraction from another, they can hardly serve as a basis for detecting adulteration presenty encountered in these products. Besides, test of thess samples based on these properties may be rather unwieldy. Adulteration of petroleum products commonly involves the deliberate and arbitrary mixture of one liquid fraction with another by individuals who seek to maximize profit in situations of product scarcity. PMS, HHK, and AGO are the major products usually adulterated as they are often in high demand for domestic and industrial purposes. The consequences of the adulteration of those products are usually grave as the practice has led to many fatal domestic and fire incidents and caused serion: damage to several automobile engines and olhe: industrial machines. In determining some physicel properties of these petroleum products (such as refraciv. indices, density, and electrical resistance) during the course of this study, it was observed that relative density is a sufficiently discriminating physical property of these products. This study, therefore, provides a useful basis for which the rampant cases of petroleum products adulteration often witnessed during perennial productis scarcity can be checked or minimized.

\section{MATERIALS AND METHODS}

\section{Equipment}

The working of the float, which is a vital component of every hydrometer, is based on the familiz" principle of flotation. In this, every floating object displaces its own weight of the fluid in which it is immersed (Nelkon. 1977). In other words, the depth to which a given object of mass $M$ will sink in any given fluid in which if floats will depend on the density $p$ of the fluid and this is expressed as

$\rho=\frac{4 M}{\pi d^{2}}$ 


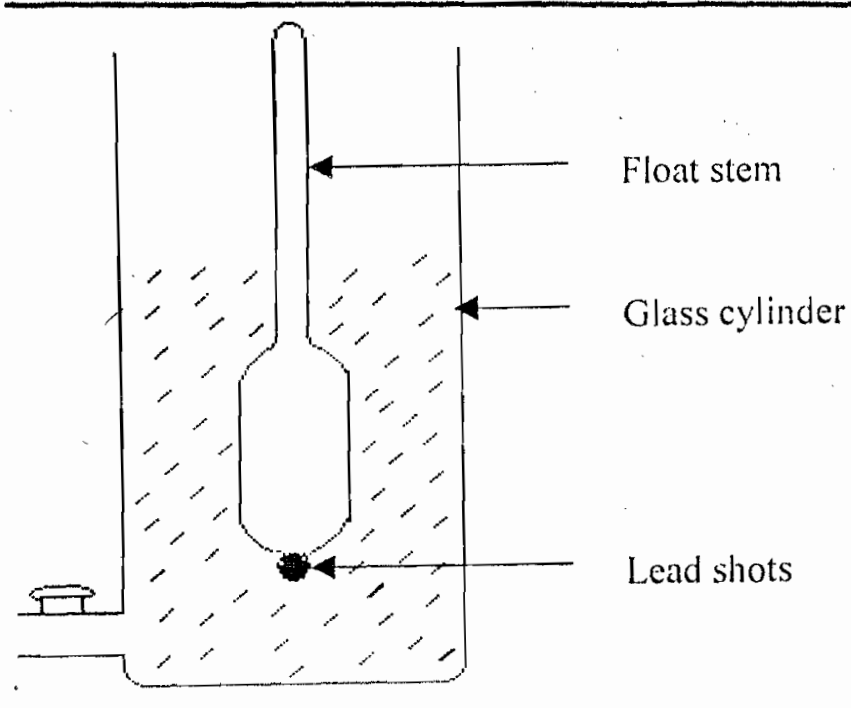

Fig. 1. Diagram showing the float

where $M$ represents the mass of the float (equal to the mass of the fluid displaced by the float) having a stem of diameter $\mathrm{d} ; \mathrm{l}$ is the depth (with respect to a reference) which the float sinks in a given liquid of density $p$. Since $d$ and $M$ are usually constant for a given float, the density of a given sample can therefore be determined by noting the depth to which the hydrometer sinks in the sample solution. The above relationship also indicates an inverse square relationship between the diameter of the stem of a floating bulb and the depth it will sink in a given liquid. In other words, a given float can be made to respond more sensitively by way of its depth variation in different liquids (particularly those with a close density range as is the case with petroleum products) if the stem diameter of the float (bulb) is made as small as possible.

The float is designed much like the hydrometer bul'b, except that it is not intended for direct determination of relative densities. It was produced at the University of Calabar glass blowing unit using a light Pyrex glass with very narrow stem. The bulb has a buoyancy chamber at its base filled with lead shot to enable it float upright. The floating stem of $290 \mathrm{~mm}$ total length has a diameter of $0.7 \mathrm{~mm}$ an's carries a scale calibrated in millimetre for direct reading of depth changes (see Fig. 1).

\section{Samples and Sampling}

Pure samples of petroleum products comprising lubricant (engine oil), automobile gasoline oil (diesel), household kerosene (kerosene), and petroleum methylated spirit (petrol), were obtained from the Nigerian National Petroleum Corporation (NNPC) depot, Calabar, and Mobil Producing Nigeria Unlimited. Eket. Samples used for analyses are required to be free from any form of contaminants, including contamination by atmospheric impurities (Considine, 1974). These samples, which were collected using the thief-can apparatus specially designed for the collection of pure samples from the storage tanks, were subsequently transported in carefully sealed, clean, and well labelled sample bottles to the laboratory for the adulteration tests and measurement of some physical parameters

\section{Relative Density Determination}

The laboratory determination of the relative densities of the petroleum products was carried out using a $50 \mathrm{~cm}^{3}$ relative density bottle which had been carefully cleaned (using soap solution) and dried.

Using the float, adulteration test was conducted on PMS, HHK, and AGO, which are the most commonly used products. For PMS, $250 \mathrm{ml}$ of its pure sample was poured into a glass cylinder with the float inserted. The depth to which the float (Fig. 1) sank in the PMS was noted as the reference for a pure, unadulterated PMS product. The PMS was then adulterated with some quantity of $A G O$ introduced into it in steps of $5 \mathrm{ml}$ until a noticeable change was observed in the depth of the float. The percentage volume of contaminant producing such change was recorded. With the mixture drained and the components thoroughly cleaned, the procedure was repeated with HHK as the contaminant and, then after, with the lubricant as the contaminant. The cylinder and the float were again wiped and the entire process described above was repeated with pure sample of HHK using PMS, AGO, and lubricant as the contaminants in each case.

\section{RESULTS AND DISCUSSION}

The results of the measurements shown in Table 1 were significant in the designing of the float used in the adulteration test. Tables 2 shows the sensitivity (in volume ratio or percentage volume of contaminant per $250 \mathrm{ml}$ volume of pure sample) of the float to different contaminants in pure samples of PMS and HHK.

Table 2 is a summary of the results obtained when HHK was adulterated using quantities of PMS, $A G O$, and lubricant respectively and when adulterating pure PMS $(250 \mathrm{ml})$ sample with $\mathrm{AGO}$, HHK, and lubricant. Sensitivity of the float to $A G O$ and lubricant contaminants are the same; that is, noticeable change in depth of the float was observed for these two contaminants when $10 \mathrm{ml}$ each of these products were introduced into HHK, indicating $4 \%(1: 25)$ of contaminant by volume of pure sample. Sensitivity was lower for PMS as $15 \mathrm{ml}$ of PMS (i.e. $6 \%$ by volume of contaminant in $250 \mathrm{mi}$ pure HHK sample or volume ratio of 3:50) was required for the float to produce a noticeable change in depth of its floating stem. This is to be expected because of the fact trlat the difference between the relative densities of HHK and PMS is much smaller than between HHK and Jubricant.

As expected, the sensitivity of the foat is higher in the case of adulterating pure PMS $(250 \mathrm{ml})$ sample with AGO, HHK, and lubricant. It records $2 \%(1: 50)$ for HHK and lubricant contaminants and $4 \%(1: 25)$ for AGO contarninant. This indicates a high sensitivity of the float to as low as $5 \mathrm{ml}$ of $\mathrm{HHK}$ and lubricant introduced into the PMS and $10 \mathrm{ml}$ of AGO introduced into the $250 \mathrm{ml}$ pure

Table 1: Relative density values for pure petroleum products sold in Nigeria

\begin{tabular}{lc}
\hline Petroleum product sample & Relative density \\
\hline PMS & \\
HHK & 0.7424 \\
ATK & 0.8114 \\
AGO & 0.8424 \\
Lubricant & 0.8784 \\
& 0.8970 \\
\hline
\end{tabular}


Table 2: Float sensitivity test

\begin{tabular}{|c|c|c|c|}
\hline & Contaminant & Minimum volume producing depth change (mi) & Volume ratio/percentage \\
\hline $\begin{array}{l}\text { Pure HHK } \\
\text { adulterated } \\
\text { with other } \\
\text { products }\end{array}$ & $\begin{array}{l}\text { PMS } \\
\text { Lubricant } \\
\text { AGO }\end{array}$ & $\begin{array}{l}15 \\
10 \\
10\end{array}$ & $\begin{array}{l}3: 50(6 \%) \\
1: 25(4 \%) \\
1: 25(4 \%)\end{array}$ \\
\hline $\begin{array}{l}\text { Pure PMS } \\
\text { adulterated } \\
\text { with other } \\
\text { products }\end{array}$ & $\begin{array}{l}\text { Lubricant } \\
\text { HHK } \\
\text { AGO }\end{array}$ & $\begin{array}{l}10 \\
5 \\
5\end{array}$ & $\begin{array}{l}1: 25(4 \%) \\
1: 50(2 \%) \\
1: 50(2 \%)\end{array}$ \\
\hline
\end{tabular}

PMS. The higher sensitivity recorded by the float in this case is due mainly to the fact that PMS has the lowest relative density in the series of products considered and therefore would have its density rapidly and significantly altered by any of the other, relatively denser petroleum products. . The sensitivity of between 2 and $6 \%$ contaminant volume in pure petroleum product sample recorded by the float is considered reasonably high as even its lowest sensitivity $(6 \%)$ is still within the range which other physical properties of these products (especially flash point) may not have been significantly altered.

\section{CONCLUSION}

Though petroleum products such as PMS, AGO, $H H K$, and lubricant are fairly distinguishable based on their relative densities, these densities are still within a very close range that makes it difficult for the hydrometers of conventional usage to be suitable for detecting slight adulteration involving these products. By taking into consideration stem size (diameter) as the primary factor iverning the sensitivity of a hydrometer float or bulb to density changes in any given liquid, it has been shown that minor adulteration of PMS and HHK of volume ratios between 1:50 and 3: 50 arising from the introduction of other petroleum products can be effectively detected. The simple design of the float and the ease with which it can be employed makes this instrument invaluable in checking the adulteration of petroleum products which has led to serious hazards in many domestic and industrial uses of theseproducts.

\section{REFERENCES}

Ababio, O. Y., 1985. New School Chemistry. Ibadan: AfricanaFep Publishers Ltd

Bland, F. and Davidson, R., 1967. Petroleum Processing Hand'book. New York: McGraw- Hill Book Co.

Considine, D. M. 1974. Chemical and Process Technology Encyclopedia. New York: McGraw-Hill Book Co.

Hatch, L. F. and Maters, S. 1981. From Hydrocarbons to Petrochemicals. Texas: Gulf Publishing Co.

Nelkon, M. 1977. Principles of Physics. London: CSS Bookshop and Hart Davis Educational. 